\title{
Influence of intermittent fasting on myocardial infarction-induced cardiac remodeling
}

K. Okoshi, ${ }^{1,2}$, M. D. M. Cezar ${ }^{1,2,3}$, M. A. M. Polin ${ }^{1,2}$, J. R. Paladino Jr $r^{1,2}$, P. F. Martinez ${ }^{4}$, S. A. Oliveira Jr ${ }^{4}$, A. R. R. Lima ${ }^{1,2}$, R. L. Damatto ${ }^{1,2,3}$, S. A. R. Paiva ${ }^{1,2}$, L. A. M. Zornoff', ${ }^{1,2}$ and M. P. Okoshi ${ }^{1,2^{*}}$ (D)

\begin{abstract}
Background: Information on the role of intermittent fasting (IF) on pathologic cardiac remodeling is scarce. We compared the effects of IF before and after myocardial infarction (MI) on rat cardiac remodeling and survival.

Methods: Wistar rats were intermittently fasted (food available every other day) or fed ad libitum for 12 weeks and then divided into three groups: AL - fed ad libitum; AL/IF - fed AL before MI and IF after MI; and IF - fed IF before and after MI. Echocardiogram was performed before MI and 2 and 12 weeks after surgery. Isolated hearts were evaluated in Langendorff preparations.

Results: Before surgery, body weight (BW) was lower in IF than AL. Final BW was lower in AL/IF and IF than AL. Perioperative mortality did not change between AL (31.3\%) and IF (27.3\%). Total mortality was lower in IF than AL. Before surgery, echocardiographic parameters did not differ between groups. Two weeks after surgery, Ml size did not differ between groups. Twelve weeks after MI, left ventricular (LV) diastolic posterior wall thickness was lower in AL/IF and IF than AL. The percentage of variation of echocardiographic parameters between twelve and two weeks showed that Ml size decreased in all groups and the reduction was higher in IF than AL/IF. In Langendorff preparations, LV volume at zero end-diastolic pressure (V0; AL: $0.41 \pm 0.05 ; \mathrm{AL} / \mathrm{IF}: 0.34 \pm 0.06 ; \mathrm{IF}: 0.28 \pm 0.05 \mathrm{~mL}$ ) and at $25 \mathrm{mmHg}$ end-diastolic pressure (V25; AL: $0.61 \pm 0.05 ; \mathrm{AL} / \mathrm{IF}: 0.54 \pm 0.07 ; \mathrm{IF}: 0.44 \pm 0.06 \mathrm{~mL}$ ) was lower in AL/IF and IF than AL and V25 was lower in IF than AL/F. VO/BW ratio was lower in IF than AL and LV weight/NO ratio was higher in IF than AL. Myocyte diameter was lower in AL/IF and IF than AL (AL: 17.3 $\pm 1.70 ; A L / F$ : $15.1 \pm 2.21$; IF: 13.4 $\pm 1.49 \mu \mathrm{m})$. Myocardial hydroxyproline concentration and gene expression of ANP, Serca $2 \mathrm{a}$, and a- and $\beta$-myosin heavy chain did not differ between groups.

Conclusion: Intermittent fasting initiated before or after MI reduces myocyte hypertrophy and LV dilation. Myocardial fibrosis and fetal gene expression are not modulated by feeding regimens. Benefit is more evident when intermittent fasting is initiated before rather than after MI.
\end{abstract}

Keywords: Myocardial infarction, Intermittent feeding, Langendorff preparation, Fetal gene expression, Echocardiogram, Ventricular remodeling, Heart failure, Rat, Isolated heart, Calorie restriction

\footnotetext{
* Correspondence: mpoliti@fmb.unesp.br

${ }^{1}$ Internal Medicine Department, Botucatu Medical School, Sao Paulo State

University, UNESP, Botucatu, SP, Brazil

${ }^{2}$ Departamento de Clinica Medica, Faculdade de Medicina de Botucatu,

UNESP, Rubiao Junior, S/N. CEP 18618-687, Botucatu, SP, Brazil

Full list of author information is available at the end of the article
}

C The Author(s). 2019 Open Access This article is distributed under the terms of the Creative Commons Attribution 4.0 International License (http://creativecommons.org/licenses/by/4.0/), which permits unrestricted use, distribution, and reproduction in any medium, provided you give appropriate credit to the original author(s) and the source, provide a link to the Creative Commons license, and indicate if changes were made. The Creative Commons Public Domain Dedication waiver (http://creativecommons.org/publicdomain/zero/1.0/) applies to the data made available in this article, unless otherwise stated. 


\section{Background}

Overweight and obesity prevalence has increased over recent decades in many parts of the world [1] and obesity has been associated with several comorbidities and increased mortality [2]. Many dietary regimens are used to decrease body weight and preserve a healthy body mass. Daily caloric restriction is probably the most common form of dietary restriction [3]. More recently, intermittent fasting has become an approach to energy restriction in humans [4]. Although observational data on the relationship between long-term intermittent fasting and risk of cardiometabolic disease are limited, there is evidence that both alternate-day fasting and periodic fasting may be effective for weight loss $[3,5]$. Beneficial effects on cardiovascular risk factors have been reported including reductions in body fat, and total cholesterol and triglyceride levels [3-5].

Intermittent fasting has been evaluated in experimental animals under different scenarios. Usually mice and rats are deprived of food every other day and fed ad libitum on the intervening days [6]. Even in the absence of expressive body weight loss, intermittent fasting has been associated with lifespan extension, improved glucose regulation $[7,8]$, neuroprotection for memory loss [9-11], nephroprotection [6], and increased cellular resistance to various type of stress [12].

Information regarding the role of intermittent fasting on pathologic cardiac remodeling is scarce. Rats subjected to intermittent fasting both before and after myocardial infarction have demonstrated attenuation in both cardiac remodeling and left ventricular dysfunction [13, 14]. However, whether the beneficial effects of intermittent fasting initiated before and after myocardial infarction are similar is still unclear. In this study, we compared the effects of intermittent fasting before and after myocardial infarction on rat cardiac remodeling and survival.

\section{Methods}

\section{Experimental groups}

Two month-old male Wistar rats were acquired from the Central Animal House, Botucatu Medical School, UNESP. Animals were housed in a room under controlled temperature and light/dark cycle. Experimental design was approved by the Animal Experimentation Ethics Committee of Botucatu Medical School, UNESP, SP, Brazil.

The rats were randomly distributed to be fed either every day (ad libitum, AL) or every other day (intermittent fasting, IF) with a standard rat diet. After 12 weeks of these feeding regimens, all rats were subjected to coronary artery ligation and the following three groups were created: fed ad libitum (AL); fed ad libitum before MI and intermittently fasted after MI (AL/IF); and intermittently fasted before and after MI (IF). Cardiac structures and left ventricular (LV) function were assessed by transthoracic echocardiograms before MI induction, and 2 and 12 weeks after surgery. At the end of the experiment, after anesthesia, hearts were removed and mounted in the Langendorff apparatus (AL, $n=8 ; \mathrm{AL} / \mathrm{IF}, n=9$; IF, $n=13$ ). All remaining animals were anesthetized with pentobarbital (50 mg/kg, intraperitoneal) and euthanized by thoracotomy and hearts removal. Right and left ventricles were dissected, weighed, frozen in liquid nitrogen, and kept at $-80^{\circ} \mathrm{C}$ for molecular analyzes. Since in vitro perfusion can alter myocardium tissue, hearts used in Langendorff preparations were not subjected to additional evaluation.

\section{Myocardial infarction}

After anesthesia with xylazine $(10 \mathrm{mg} / \mathrm{kg})$ and ketamine (70 mg/kg), MI was induced as described in our laboratory $[15,16]$.

\section{Echocardiographic study}

Rats were lightly anesthetized with an intraperitoneal injection of ketamine $(50 \mathrm{mg} / \mathrm{kg})$ and xylazine $(1 \mathrm{mg} / \mathrm{kg})$. Echocardiogram was performed by the same blinded examiner (KO) using a echocardiograph (General Electric Medical Systems, Vivid S6, Tirat Carmel, Israel) equipped with a $5.0-11.5 \mathrm{MHz}$ multifrequency probe, according to the previously described method [17-20]. MI size was estimated by two-dimensional image measuring end-diastolic endocardial perimeter of affected myocardium in relation to the total LV endocardial perimeter.

\section{Isolated LV study - Langendorff preparation}

One day after echocardiographic evaluation, rats were anesthetized with sodium thiopental $(50 \mathrm{mg} / \mathrm{kg}$, intraperitoneal) and heparin (2000 IU, intraperitoneal) and euthanized by thoracotomy. After removing hearts, they were mounted in the Langendorff apparatus according to the method previously described [21-23]. After recording functional data, hearts were detached, the atria and great vessels removed, and the ventricles separated and weighed [23].

\section{Morphological analysis}

Hematoxylin and eosin-stained slides from LV tissue were used to measure approximately 50 cardiomyocyte diameters as the lower distance between myocyte borders drawn across the nucleus [24-26].

\section{Myocardial hydroxyproline}

Left ventricular concentration of hydroxyproline was quantified to estimate myocardial collagen content according to a previously described method [27-29]. In brief, myocardial samples were dried and hydrolyzed 
overnight at $100{ }^{\circ} \mathrm{C}$ with $6 \mathrm{~N} \mathrm{HCl}(1 \mathrm{~mL} / 10 \mathrm{mg}$ dry tissue). Aliquots of $50 \mu \mathrm{L}$ were dried again in a Speedvac Concentrator. After adding $1.0 \mathrm{~mL}$ of deionized water and $1.0 \mathrm{~mL}$ of potassium borate buffer ( $\mathrm{pH}$ 8.7), samples were oxidized with $0.3 \mathrm{~mL}$ of chloramine $\mathrm{T}$ solution for $20 \mathrm{~min}$. The addition of $1 \mathrm{~mL}$ of $3.6 \mathrm{M}$ sodium thiosulfate stopped the oxidative process. The solution was then saturated with $1.5 \mathrm{~g}$ $\mathrm{KCl}$. The tubes were heated in boiling water for 20 min. After extracting the aqueous layer with $2.5 \mathrm{~mL}$ of toluene, $1.5 \mathrm{~mL}$ of toluene extract were added to $0.6 \mathrm{~mL}$ of Ehrlich's reagent and the color was allowed to develop for $30 \mathrm{~min}$. Absorbances were read at 565 $\mathrm{nm}$ against a reagent blank. Deionized water and hydroxyproline standard $(20 \mu \mathrm{g} / \mathrm{mL})$ were used as the blank and control, respectively.

\section{Gene expression}

To assess the fetal gene program, we analyzed sarcoplasmic reticulum calcium ATPase (Serca 2a), myocardial $\alpha$ and $\beta$-myosin heavy chain, and atrial natriuretic peptide (ANP) expression by real time RT-PCR as previously described [30-33]. Briefly, total RNA was extracted, solubilized in RNase-free $\mathrm{H}_{2} \mathrm{O}$, incubated in DNase I (Invitrogen Life Technologies), quantified and reverse transcribed. Aliquots of cDNA were submitted to realtime PCR using $10 \mu \mathrm{L} 2 \mathrm{X}$ TaqMan ${ }^{\circ}$ Universal PCR Master Mix (Applied Biosystems) and $1 \mu \mathrm{L}$ of customized assay (20X) containing sense and antisense primers and Taqman (Applied Biosystems, Foster City, CA, EUA) probe specific to the following genes: Serca2a (Taqman assay Rn00568762; Ref. seq. Genbank NM_017290), $\alpha-$ myosin (myosin heavy polypeptide 6, cardiac muscle, alpha; Taqman assay Rn00568304_m1; Ref. seq. Genbank NM_017239.1), $\beta$-myosin (myosin heavy polypeptide 7, cardiac muscle, beta; Taqman assay Rn00568328_m1; Ref. seq. Genbank NM_017240.1), and natriuretic peptide precursor type A (Taqman assay Rn00561661_m1; Ref. seq. Genbank NM_012612.1). Amplification and analysis were then performed; reactions were carried out in triplicate. After normalizing data expression to cyclophilin (Taqman assay Rn00690933_m1; Ref. seq. Genbank NM_017101), results were calculated using the CT method $\left(2^{-\Delta \Delta C T}\right)$.

\section{Statistical analyzes}

Data are expressed as mean \pm standard deviation or median and 25th and 75th percentiles in accordance with normal or non-normal distribution. Comparisons between groups were performed by analysis of variance (ANOVA) complemented by the Tukey's test or KruskalWallis and Dunn's tests for normal and non-normal distributions, respectively. Mortality was assessed by log- rank test (Kaplan Meier). Statistical significance was accepted at the level of $p<0.05$.

\section{Results}

Initial body weight (BW) did not differ between groups (Table 1). Before surgery, BW was lower in IF than AL and AL/IF groups. At the end of the experiment, AL/IF and IF had lower BW than AL. Perioperative mortality rate including the first $24 \mathrm{~h}$ after surgery did not change between AL (31.3\%) and IF (27.3\%) groups. At the end of the experiment, mortality rate was lower in IF than AL (Fig. 1).

Before surgery, echocardiographic parameters of cardiac structure and function did not differ between $\mathrm{AL}$ and IF (data not shown). Echocardiographic data two weeks after MI induction are shown in Table 2. Isovolumic relaxation time in absolute and normalized to heart rate values were higher in IF than $\mathrm{AL}$ and $\mathrm{AL} / \mathrm{IF}$ groups. Echocardiographic data 12 weeks after MI are shown in Table 3. LV diastolic posterior wall thickness was lower in $\mathrm{AL} / \mathrm{IF}$ and IF than AL. E-wave deceleration time was lower in AL/IF than AL and IF. Myocardial infarction size did not differ between groups. The percentage of variation $(\Delta)$ of echocardiographic parameters between twelve and two weeks post-infarction was calculated as [(final value minus initial value)/initial value] X 100 (Table 4). $\Delta \mathrm{BW}$ increased in all groups; the increase was higher in IF than AL/IF. $\Delta$ MI size decreased in all groups; the reduction in MI size was higher in IF than AL/IF.

Isolated heart functional study data are presented in Table 5 and Fig. 2. $V_{0}$ and $V_{25}$ were lower in AL/IF and IF than AL and $V_{25}$ was lower in IF than AL/IF; when normalized to BW, $\mathrm{V}_{0}$ was lower in IF than AL (Fig. 2). $\mathrm{LV}$ weight normalized to $\mathrm{V}_{0}$ was higher in IF than AL (Table 4).

Myocyte diameter was lower in $\mathrm{AL} / \mathrm{IF}$ and IF than $\mathrm{AL}$ (AL 17.3 $\pm 1.70 ; \mathrm{AL} / \mathrm{IF} 15.1 \pm 2.21$; IF $13.4 \pm 1.49 \mu \mathrm{m} ; p<$ $0.05 \mathrm{AL} / \mathrm{IF}$ and IF vs $\mathrm{AL}$ ). Myocardial hydroxyproline concentration (AL 5.35 \pm 2.39 ; AL/IF $8.16 \pm 1.16$; IF 7.39 $\pm 3.19 \mu \mathrm{g} / \mathrm{mg}$ myocardial tissue) and gene expression of ANP, Serca $2 a$, and $\alpha$ - and $\beta$-myosin heavy chain (Table 6) did not differ between groups.

Table 1 Body weight (g)

\begin{tabular}{llll}
\hline & $\mathrm{AL}$ & $\mathrm{AL} / \mathrm{IF}$ & $\mathrm{IF}$ \\
\hline Initial & $283 \pm 44$ & $282 \pm 39$ & $281 \pm 37$ \\
Before surgery & $469 \pm 45$ & $459 \pm 48$ & $362 \pm 33^{* *}$ \\
Before euthanasia & $481 \pm 47$ & $391 \pm 41^{*}$ & $397 \pm 45^{*}$ \\
\hline
\end{tabular}

Data as mean \pm standard deviation. $A L$ ad libitum fed, $A L / I F$ ad libitum before myocardial infarction (MI) and intermittently fasted after MI, IF intermittently fasted before and after MI. ANOVA and Tukey; ${ }^{*} p<0.05$ vs AL; ${ }^{*} p<0.05$ vs AL/IF 


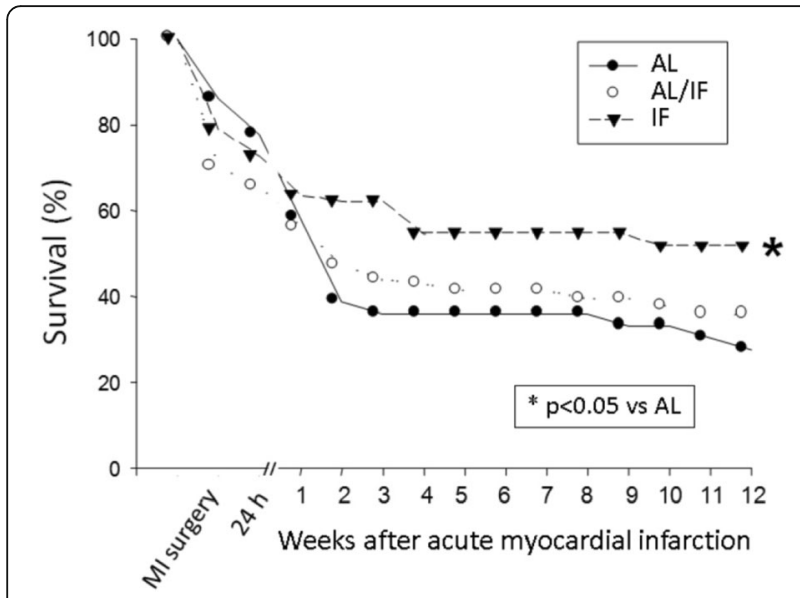

Fig. 1 Kaplan-Meier curves for rat survival after myocardial infarction induction. AL: ad libitum fed; AL/IF: ad libitum before myocardial infarction (MI) and intermittently fasted after MI; IF: intermittently fasted before and after $\mathrm{Ml}$

\section{Discussion}

The novel design of this study is the comparison of intermittent fasting initiated before and after myocardial infarction on rat cardiac remodeling.

Caloric restriction has long been shown to increase lifespan in rodents [34]. Moderate caloric restriction was associated with cardiac ageing delay, improved pressure overload-induced cardiac remodeling, and better myocardial ischemic tolerance [35-39]. On the other hand, severe caloric restriction impaired structural and functional parameters in spontaneously hypertensive rats [40]. Only more recently were cardiovascular parameters analyzed in rodents under intermittent fasting. Intermittent fasting in normal rats produced controversial results. Castello et al. [41] observed protection against age-induced inflammation, fibrosis, and oxidative stress in rat hearts. In contrast, increased fibrosis with diastolic dysfunction and diminished cardiac reserve were observed after six months of alternate-day fasting [42].

Body weight in intermittently fasted rats is usually lower than their ad libitum fed counterparts [13, 14]. In this study, AL/IF and IF groups had body weights approximately $18 \%$ lower than AL. However, body weight did not differ between rats that were subjected to intermittent fasting for 12 and 24 weeks showing that body weight loss following intermittent fasting is limited.

We have previously characterized myocardial infarctioninduced cardiac remodeling in rats with large infarction size, usually characterized as an infarcted area greater than $40 \%$ of total LV area $[15,43,44]$. Six months after MI induction, rats with large MI present LV and left atrial dilation, LV diastolic posterior wall thickness increase, and systolic and diastolic dysfunction [15, 31, 43]. Feeding regimen in this study did not change MI size as all groups had large infarction size. This finding diverges from those

Table 2 Echocardiographic evaluation two weeks after myocardial infarction

\begin{tabular}{|c|c|c|c|}
\hline & $\mathrm{AL}(n=35)$ & $\mathrm{AL} / \mathrm{IF}(n=39)$ & $\mathrm{IF}(n=40)$ \\
\hline$\overline{B W}(\mathrm{~g})$ & $439 \pm 51$ & $397 \pm 44^{*}$ & $344 \pm 23^{* \#}$ \\
\hline HR (beats/min) & $287 \pm 27$ & $280 \pm 47$ & $286 \pm 34$ \\
\hline LVDD (mm) & $10.9 \pm 0.87$ & $10.9 \pm 0.77$ & $10.6 \pm 0.99$ \\
\hline LVSD (mm) & $8.94 \pm 1.16$ & $8.99 \pm 1.03$ & $8.50 \pm 1.37$ \\
\hline LVDPWT (mm) & $1.52 \pm 0.15$ & $1.51 \pm 0.14$ & $1.48 \pm 0.14$ \\
\hline $\mathrm{LA}(\mathrm{mm})$ & $8.14 \pm 0.86$ & $8.14 \pm 1.09$ & $8.00 \pm 1.23$ \\
\hline E-wave $(\mathrm{cm} / \mathrm{s})$ & $100(93.5-118)$ & $100(91.0-110)$ & $96.0(81.0-110)$ \\
\hline A-wave $(\mathrm{cm} / \mathrm{s})$ & $20.0(15.0-48.5)$ & $19.0(15.3-31.8)$ & $19.0(17.0-49.0)$ \\
\hline E/A & $5.50(2.12-7.04)$ & $5.79(2.97-6.80)$ & $5.17(1.54-6.32)$ \\
\hline IVRT (ms) & $29.3 \pm 4.06$ & $30.8 \pm 6.56$ & $34.7 \pm 5.90^{* \#}$ \\
\hline IVRTn & $64.2 \pm 10.5$ & $66.5 \pm 14.9$ & $75.4 \pm 12.8^{* \#}$ \\
\hline EDT (ms) & $39.0(30.8-44.3)$ & $34.5(27.0-39.0)$ & $33.0(30.0-39.0)$ \\
\hline LV diastolic area $\left(\mathrm{cm}^{2}\right)$ & $0.91 \pm 0.14$ & $0.91 \pm 0.15$ & $0.88 \pm 0.17$ \\
\hline LV systolic área $\left(\mathrm{cm}^{2}\right)$ & $0.64 \pm 0.14$ & $0.64 \pm 0.13$ & $0.61 \pm 0.15$ \\
\hline$\Delta$ Area (\%) & $30.2 \pm 7.77$ & $30.8 \pm 7.07$ & $30.4 \pm 9.10$ \\
\hline Ml size (\% of total LV area) & $50.0 \pm 7.64$ & $51.4 \pm 6.66$ & $52.3 \pm 11.9$ \\
\hline
\end{tabular}

Data as mean \pm standard deviation or median and 25th and 75th percentiles. $A L$ ad libitum fed, $A L / I F$ ad libitum before myocardial infarction (MI) and intermittently fasted after MI, IF intermittently fasted before and after MI. BW body weight, HR heart rate, LVDD and LVSD left ventricular (LV) diastolic and systolic diameters, respectively, LVDPWT LV diastolic posterior wall thickness, LA left atrial diameter, E-wave and A-wave early and late diastolic mitral inflow, respectively, IVRT isovolumic relaxation time, IVRTn IVRT normalized to heart rate, EDT E-wave deceleration time; $\triangle$ Area: fractional area change. ANOVA and Tukey or KruskalWallis and Dunn; * $p<0.05$ vs AL; $\# p<0.05$ vs AL/IF 
Table 3 Echocardiographic evaluation twelve weeks after myocardial infarction

\begin{tabular}{|c|c|c|c|}
\hline & $\mathrm{AL}(n=26)$ & $\mathrm{AL} / \mathrm{IF}(n=28)$ & $\mathrm{IF}(n=20)$ \\
\hline BW (g) & $479 \pm 58$ & $393 \pm 41^{*}$ & $387 \pm 28^{*}$ \\
\hline HR (beats/min) & $283 \pm 41$ & $279 \pm 26$ & $261 \pm 25^{*}$ \\
\hline LVDD (mm) & $11.1 \pm 0.98$ & $10.7 \pm 1.34$ & $10.7 \pm 0.62$ \\
\hline LVSD (mm) & $8.87 \pm 1.32$ & $8.66 \pm 1.75$ & $8.82 \pm 1.13$ \\
\hline LVDPWT (mm) & $1.64 \pm 0.14$ & $1.48 \pm 0.15^{*}$ & $1.48 \pm 0.17^{*}$ \\
\hline $\mathrm{LA}(\mathrm{mm})$ & $8.25 \pm 1.48$ & $7.92 \pm 1.50$ & $7.70 \pm 1.17$ \\
\hline E-wave $(\mathrm{cm} / \mathrm{s})$ & $95.2 \pm 28.0$ & $88.9 \pm 19.9$ & $82.2 \pm 21.9$ \\
\hline A-wave $(\mathrm{cm} / \mathrm{s})$ & $27.0(19.0-43.0)$ & $17.0(14.5-38.5)$ & $26.0(15.0-46.0)$ \\
\hline$E / A$ & $3.99(1.37-5.46)$ & $5.77(1.68-6.73)$ & $3.18(1.48-6.63)$ \\
\hline IVRT (ms) & $34.8 \pm 5.48$ & $34.3 \pm 7.00$ & $33.3 \pm 6.59$ \\
\hline IVRTn & $75.4 \pm 12.6$ & $73.7 \pm 15.0$ & $69.4 \pm 13.7$ \\
\hline EDT (ms) & $36.0(33.0-41.5)$ & $30.0(27.0-38.8)^{*}$ & $36.0(33.0-42.0)^{\#}$ \\
\hline LV diastolic area $\left(\mathrm{cm}^{2}\right)$ & $1.01 \pm 0.18$ & $0.94 \pm 0.23$ & $0.90 \pm 0.18$ \\
\hline LV systolic area $\left(\mathrm{cm}^{2}\right)$ & $0.68 \pm 0.18$ & $0.66 \pm 0.21$ & $0.60 \pm 0.15$ \\
\hline$\Delta$ Area $(\%)$ & $33.0 \pm 8.91$ & $30.8 \pm 9.92$ & $33.5 \pm 7.74$ \\
\hline MI size (\% of total LV area) & $45.4 \pm 8.67$ & $48.4 \pm 11.5$ & $43.6 \pm 9.90$ \\
\hline
\end{tabular}

Data as mean \pm standard deviation or median and 25th and 75th percentiles. AL ad libitum fed, AL/IF ad libitum before myocardial infarction (MI) and intermittently fasted after MI. IF intermittently fasted before and after MI. BW body weight, HR heart rate, LVDD and LVSD left ventricular (LV) diastolic and systolic diameters, respectively, LVDPWT LV posterior wall thickness, LA left atrial diameter, E-wave and A-wave early and late diastolic mitral inflow, respectively, IVRT isovolumic relaxation time, IVRTn IVRT normalized to heart rate, EDT: E-wave deceleration time; $\triangle$ Area: fractional area change. ANOVA and Tukey or Kruskal-Wallis and Dunn; ${ }^{*} p<0.05$ vs AL; \# $p<0.05$ vs AL/IF

Table 4 Percentage of variation $(\Delta)$ of echocardiographic parameters between twelve and two weeks post-infarction

\begin{tabular}{llll}
\hline & $\mathrm{AL}(n=26)$ & $\mathrm{AL} / \mathrm{IF}(n=28)$ & $\mathrm{IF}(n=20)$ \\
\hline BW & $7.86(4.17-11.6)$ & $4.35(-2.61-6.90)$ & $11.0(9.57-13.0)^{\#}$ \\
HR & $4.73 \pm 15.4$ & $4.25 \pm 17.0$ & $-7.91 \pm 8.00^{* \#}$ \\
LVDD & $7.61 \pm 5.14$ & $2.33 \pm 8.45$ & $2.85 \pm 6.47$ \\
LVSD & $6.02 \pm 12.1$ & $3.07 \pm 13.2$ & $6.75 \pm 10.7$ \\
LA & $8.40 \pm 17.1$ & $4.74 \pm 9.87$ & $-1.43 \pm 15.0$ \\
E-wave & $7.65 \pm 33.9$ & $-5.71 \pm 17.2$ & $-14.4 \pm 14.5^{*}$ \\
A-wave & $18.6(-11.1-86.7)$ & $-6.97(-23.0-12.7)$ & $-1.02(-34.8-31.2)$ \\
E/A & $0.23(-47.5-15.1)$ & $-8.14(-25.6-37.7)$ & $-4.78(-34.2-29.2)$ \\
IVRT & $14.6 \pm 21.0$ & $3.90 \pm 22.9$ & $-2.96 \pm 21.9$ \\
IVRTn & $16.7 \pm 21.1$ & $5.21 \pm 22.3$ & $-7.08 \pm 20.7^{*}$ \\
EDT & $-6.13 \pm 20.7$ & $-11.1 \pm 20.7$ & $12.2 \pm 30.6^{\#}$ \\
LV diastolic area & $10.6 \pm 12.0$ & $8.89 \pm 14.7$ & $5.27 \pm 18.5$ \\
LV systolic area & $8.37 \pm 22.9$ & $12.1 \pm 19.9$ & $3.17 \pm 19.0$ \\
$\Delta$ Area & $9.13 \pm 30.0$ & $-3.06 \pm 29.9$ & $9.06 \pm 35.0$ \\
MI size & $-9.76(-14.9--2.49)$ & $-4.13(-12.9-9.51)$ & $-13.2(-23.7--6.52)^{\#}$ \\
\hline
\end{tabular}

Data as mean \pm standard deviation or median and 25th and 75th percentiles. AL: ad libitum fed; AL/F: ad libitum before myocardial infarction (MI) and intermittently fasted after MI; IF: intermittently fasted before and after MI. $\Delta$ was calculated as [(final value minus initial value)/initial value] X 100. BW: body weight; HR: heart rate; LVDD and LVSD: left ventricular (LV) diastolic and systolic diameters, respectively; LA: left atrial diameter; E-wave and A-wave: early and late diastolic mitral inflow, respectively; IVRT: isovolumic relaxation time; IVRTn: IVRT normalized to heart rate; EDT: E-wave deceleration time; $\triangle$ Area: fractional area change. ANOVA and Tukey or Kruskal-Wallis and Dunn; ${ }^{*} \mathrm{p}<0.05$ vs AL; $\# p<0.05$ vs AL/IF 
Table 5 Isolated heart functional study

\begin{tabular}{llll}
\hline & AL $(n=8)$ & AL/IF $(n=9)$ & IF $(n=13)$ \\
\hline BW $(\mathrm{g})$ & $458 \pm 35$ & $404 \pm 39^{*}$ & $389 \pm 32^{*}$ \\
LWW $(\mathrm{g})$ & $1.05 \pm 0.12$ & $1.06 \pm 0.21$ & $0.99 \pm 0.13$ \\
LWW/BW $(\mathrm{g} / \mathrm{kg})$ & $2.29 \pm 0.13$ & $2.62 \pm 0.40$ & $2.54 \pm 0.32$ \\
$\mathrm{LWWN}_{0}(\mathrm{~g} / \mathrm{mL})$ & $2.56(2.18-2.90)$ & $2.90(2.54-3.92)$ & $3.35(3.11-3.75)^{*}$ \\
$\mathrm{DP}_{0}(\mathrm{mmHg})$ & $44.7 \pm 16.9$ & $30.8 \pm 11.6$ & $41.4 \pm 16.7$ \\
$\mathrm{DP}_{25}(\mathrm{mmHg})$ & $53.6 \pm 22.3$ & $50.0 \pm 17.8$ & $53.0 \pm 26.5$ \\
$\mathrm{DP}_{\max }$ & $58.3 \pm 22.0$ & $51.4 \pm 18.0$ & $56.3 \pm 25.0$ \\
$+\mathrm{dP} / \mathrm{dt}(\mathrm{mmHg} / \mathrm{s})$ & $1562 \pm 590$ & $1034 \pm 385$ & $1495 \pm 643$ \\
Systolic stress & $\left(\mathrm{g} / \mathrm{cm}^{2}\right)$ & $70.0 \pm 31.0$ & $65.0 \pm 33.4$ \\
$-\mathrm{dP} / \mathrm{dt}(\mathrm{mmHg} / \mathrm{s})$ & $80.8 \pm 30.0$ & $562 \pm 283$ & $831 \pm 341$ \\
$\Delta V_{25}(\%)$ & $1000 \pm 340$ & $61.0 \pm 21.5$ & $57.0 \pm 17.3$ \\
Strain $20 \mathrm{~g} / \mathrm{cm}^{2}(\%)$ & $49.0 \pm 6.20$ & $7.50 \pm 2.19$ & $7.00 \pm 1.88$ \\
\hline
\end{tabular}

Data as mean \pm standard deviation or median and 25th and 75th percentiles. AL ad libitum fed, $A L / I F$ ad libitum before myocardial infarction (MI) and intermittently fasted after MI, IF intermittently fasted before and after MI. BW body weight, $L V W$ left ventricular (LV) weight, $D P_{0}$ LV developed pressure at zero diastolic pressure, $D P_{25} \mathrm{LV}$ developed pressure at diastolic pressure of $25 \mathrm{mmHg}, D P_{\text {max }}$ maximum developed pressure, $+d P / d t$ maximum rate of pressure development; Systolic stress $25 \mathrm{LV}$ systolic stress at diastolic pressure of $25 \mathrm{mmHg},-d P / d t$ maximum rate of ventricular pressure decline, $\Delta V_{25}$ percentage of variation in LV volume required to increase diastolic pressure from 0 to $25 \mathrm{mmHg}$, Strain $20 \mathrm{~g} / \mathrm{cm}^{2}$ percentage of myocardial strain caused by a diastolic stress of $20 \mathrm{~g} / \mathrm{cm}^{2}$. ANOVA and Tukey or Kruskal-Wallis and Dunn; * $p<0.05$ vs AL; \# $p<0.05$ vs AL/IF

by Ahmet et al. [13] who found smaller infarction size in intermittent fasted rats $24 \mathrm{~h}$ after $\mathrm{MI}$ induction. Our first evaluation of MI size was performed two weeks after MI. At this time, mortality was lower in IF than AL and AL/IF groups. Therefore, it is possible that rats with larger MI size in AL and AL/IF groups had already died before our first evaluation. Mortality throughout the 12 weeks postinfarction was lower in IF than AL; the AL/IF group had intermediate mortality and did not differ from both $\mathrm{AL}$ and IF groups.

Two weeks after MI induction, echocardiographic parameters did not differ between groups, except for a higher isovolumic relaxation time in the IF group. Twelve weeks after MI, LV diastolic posterior wall thickness was lower in AL/IF and IF than AL, showing that intermittent fasting attenuated myocardial hypertrophy. This finding was corroborated by lower myocyte diameter in both AL/IF and IF groups. When comparing changes in echocardiographic parameters between twelve and two weeks post-infarction, IF had a better remodeling than AL and AL/IF. This was characterized by a decrease in $\Delta \mathrm{E}$-wave and in $\Delta \mathrm{MI}$ size and an increase in $\Delta \mathrm{E}$-wave deceleration time (EDT). As E/A ratio increases and EDT decreases in large infarctions [43], the changes in these parameters between both evaluations suggest a beneficial effect of intermittent fasting on diastolic function.

Results from Langendorff preparations confirmed a better effect of intermittent fasting when started before MI. $V_{0}$ and $V_{25}$ were lower in both intermittent fasted groups and $V_{25}$ was lower in IF than AL/IF. These parameters indicate the $\mathrm{LV}$ volume at zero and $25 \mathrm{mmHg}$ end-diastolic pressure, respectively. Furthermore, LV weight $/ V_{0}$ ratio was higher and $V_{0}$ /body weight ratio lower in IF than AL, suggesting a predominance of concentric over eccentric remodeling in the IF group. These data show that, despite the same MI size and therefore the same degree of ischemia-induced myocardial injury, intermittent fasting reduced LV cavity size, thus attenuating cardiac remodeling, and this attenuation was more intense in IF than AL/IF.

As potential mechanisms involved in cardiac remodeling attenuation, we evaluated myocardial expression of fetal genes and cardiac fibrosis. Interestingly, improvement in cardiac remodeling was not associated with changes in expression of the fetal genes $\alpha$ - and $\beta$-myosin heavy chain, atrial natriuretic peptide or Serca 2a. Reactivation of the fetal gene program is considered to be involved in adverse cardiac remodeling and the pathogenesis of heart failure [45]. Therefore, our results show that fetal gene program changes are not modulated by intermittent fasting. In the same way, myocardial hydroxyproline concentration, a marker of interstitial fibrosis, was not affected by dietary intervention. The effect of intermittent fasting on myocardial fibrosis is controversial, as both increased [42] and reduced [40] fibrosis was observed in healthy rats.

Attenuation of cardiac remodeling has previously been observed in rats subjected to intermittent fasting either before MI induction [13] or two weeks after MI [14]. As Ahmet et al. [13] reported, intermittent fasting reduced MI size therefore attenuating all aspects of cardiac remodeling. However, even in rats with similar MI sizes, intermittent fasting reduced myocyte apoptosis and 


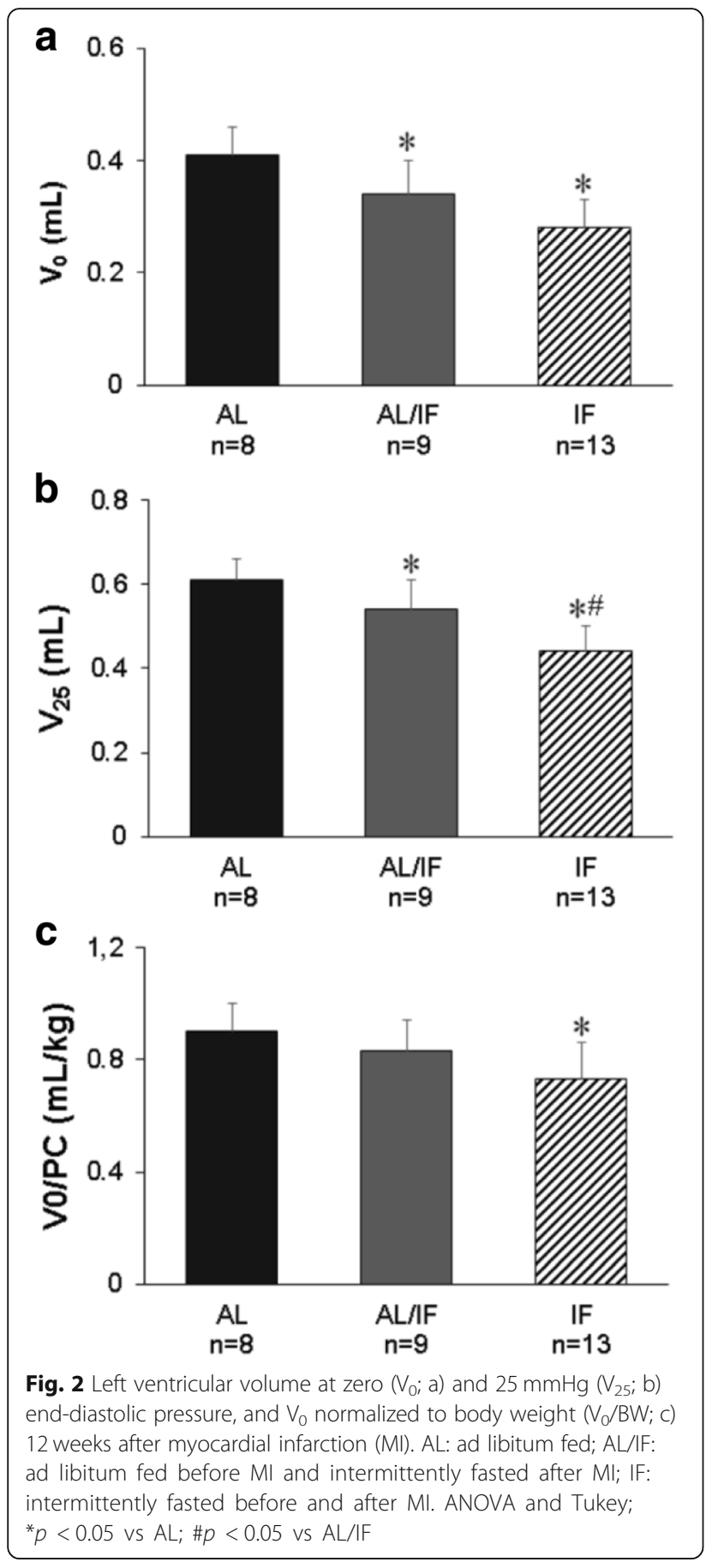

neutrophil infiltration in the area at ischemia risk when compared to the ad libitum regimen [13].

Intermittent fasting initiated two weeks after MI accelerated pro-angiogenic and cell survive cascades [14]. To the best of our knowledge, this is the first study to show that the effects of intermittent fasting initiated before MI are more evident than when initiated after MI. Although both regimens decreased mortality, only when started before MI did intermittent fasting reach statistical significance.
Table 6 Gene expression

\begin{tabular}{llll}
\hline & AL $(n=5)$ & AL/IF $(n=6)$ & $\mathrm{IF}(\mathrm{n}=6)$ \\
\hline ANP & $1.00 \pm 0.47$ & $0.74 \pm 0.16$ & $0.58 \pm 0.07$ \\
Serca 2a & $1.00 \pm 0.20$ & $1.17 \pm 0.15$ & $1.09 \pm 0.07$ \\
a-MHC & $1.00 \pm 0.17$ & $1.01 \pm 0.17$ & $0.90 \pm 0.10$ \\
B-MHC & $1.00 \pm 0.25$ & $0.78 \pm 0.07$ & $0.72 \pm 0.12$
\end{tabular}

Data as mean \pm standard deviation. $A L$ ad libitum fed, $A L / I F$ ad libitum before myocardial infarction (MI) and intermittently fasted after MI, IF intermittently fasted before and after MI. ANP atrial natriuretic peptide, Serca $2 a$ sarcoplasmic reticulum calcium ATPase, $M H C$ myosin heavy chain. ANOVA

Both fasting regimens reduced myocyte hypertrophy and LV dilation. However, the IF group also had evidence of decreased MI size, concentric remodeling predominating over eccentric remodeling, and better diastolic function evolution than AL/IF rats. Additional studies are needed to clarify the mechanisms involved in the attenuation of myocardial infarction-induced cardiac remodeling.

\section{Conclusion}

Intermittent fasting initiated before or after myocardial infarction reduces myocyte hypertrophy and left ventricular dilation in rats. Myocardial fibrosis and fetal gene expression are not modulated by the feeding regimens. Benefit is more evident when intermittent fasting is initiated before than after myocardial infarction.

\section{Abbreviations \\ $+\mathrm{dP} / \mathrm{dt}$ : Maximum rate of pressure development; AL: Ad libitum; ANOVA: Analysis of variance; ANP: Atrial natriuretic peptide; -dP/dt: Maximum rate of ventricular pressure decline; $E$ and $A$ waves: Early and late, respectively, diastolic mitral inflow velocities; EDT: E-wave deceleration time; IF: Intermittent fasting; IM: Myocardial infarction; IVRT: Isovolumetric relaxation time; IVRTn: IVRT normalized to heart rate; LA: Left atrial diameter; LV: Left ventricular; LVDD and LVSD: LV diastolic and systolic dimensions, respectively; LVDPWT: LV diastolic posterior wall thickness; LW: LV volume; LWW: LV weight; $V_{0}$ : LV volume at zero end-diastolic pressure; $V_{25}$ : LV volume at $25 \mathrm{mmHg}$ end-diastolic pressure; $\Delta$ area: Fractional area change; $\Delta$ $V_{25}$ : Percentage of variation in LV volume required to increase diastolic pressure from 0 to $25 \mathrm{mmHg}$; $\Delta$ : Percentage of variation.}

\section{Acknowledgments}

The authors are grateful to Jose Carlos Georgette for his technical assistance and Colin Edward Knaggs for English editing.

\section{Consent to participate}

Not applicable.

\section{Consent to publish}

Not Applicable.

\section{Authors' contributions}

$\mathrm{KO}, \mathrm{MAMP}$, and JRP Jr. contributed to study conception and design, and data acquisition, analysis and interpretation; KO, MDMC, and MPO contributed to manuscript writing; PFM, ARRL, RLD, and LAMZ contributed to data collection; MPO, SAO Jr. and SARP contributed to data analysis; KO contributed to study funding. All authors read and approved the final manuscript.

\section{Funding}

Financial support was provided by FAPESP (Proc. n. 2007/58426-2, 2007/ 58425-6, and 2008/50418-3), CNPq (Proc. n. 306770/2015-6 and 308674/ 2015-4), CAPES, and PROPe, UNESP. The funding sources had no 
involvement in study design; data collection, analysis and interpretation; or report writing.

\section{Availability of data and materials}

The datasets used and/or analysed during the current study available from the corresponding author on request.

\section{Ethics approval}

All experiments and procedures were approved by the Ethics Committee of Botucatu Medical School, Sao Paulo State University, UNESP, Botucatu, SP, Brazil.

\section{Competing interests}

The authors declare that they have no competing interests.

\section{Author details}

'Internal Medicine Department, Botucatu Medical School, Sao Paulo State University, UNESP, Botucatu, SP, Brazil. ²Departamento de Clinica Medica, Faculdade de Medicina de Botucatu, UNESP, Rubiao Junior, S/N. CEP 18618-687, Botucatu, SP, Brazil. ${ }^{3}$ Itapeva Social and Agrarian Sciences College, FAIT, Itapeva, SP, Brazil. ${ }^{4}$ Federal University of Mato Grosso do Sul, Cidade Universitária, Av. Costa e Silva - Pioneiros, Campo Grande, MS 79070-900, Brazil.

Received: 16 January 2019 Accepted: 20 May 2019

Published online: 28 May 2019

\section{References}

1. Hales CM, Fryar CD, Carroll MD, et al. Trends in obesity and severe obesity prevalence in us youth and adults by sex and age, 2007-2008 to 2015-2016. JAMA. 2018;319:2410-8.

2. Upadhyay J, Farr O, Perakakis N, et al. Obesity as a disease. Med Clin North Am. 2018;102:13-33.

3. Tinsley GM, La Bounty PM. Effects of intermittent fasting on body composition and clinical health markers in humans. Nutr Rev. 2015;73: $661-74$

4. Tinsley GM, Horne BD. Intermittent fasting and cardiovascular disease: current evidence and unresolved questions. Futur Cardiol. 2018;14:47-54.

5. St-Onge MP, Ard J, Baskin ML, et al. American Heart Association obesity Committee of the Council on lifestyle and Cardiometabolic health; council on cardiovascular disease in the young; council on clinical cardiology; and stroke council. Meal timing and frequency: implications for cardiovascular disease prevention. A scientific statement from the American Heart Association. Circulation. 2017;135:e96-e121.

6. Tikoo K, Tripathi DN, Kabra DG, et al. Intermittent fasting prevents the progression of type 1 diabetic nephropathy in rats and changes the expression of Sir2 and p53. FEBS Lett. 2007;581:1071-8.

7. Wan R, Camandola S, Mattson MP. Intermittent fasting and dietary supplementation with 2-deoxy-d-glucose improve functional and metabolic cardiovascular risk factors in rats. FASEB J. 2003;17:1133-4

8. Wan $\mathrm{R}$, Ahmet I, Brown M, et al. Cardioprotective effect of intermittent fasting is associated with an elevation of adiponectin levels in rats. J Nutr Biochem. 2010;21:413-7.

9. Castrogiovanni P, Li Volti G, Sanfilippo C, et al. Fasting and fast food diet play an opposite role in mice brain aging. Mol Neurobiol. 2018;55:6881-93.

10. Hu $Y$, Yang $Y$, Zhang $M$, et al. Intermittent fasting pretreatment prevents cognitive impairment in a rat model of chronic cerebral hypoperfusion. J Nutr. 2017;147:1437-45.

11. Hu Y, Zhang M, Chen $Y$, et al. Postoperative intermittent fasting prevents hippocampal oxidative stress and memory deficits in a rat model of chronic cerebral hypoperfusion. Eur J Nutr. 2018;58:423-32.

12. Mattson MP, Chan SL, Duan W. Modification of brain aging and neurodegenerative disorders by genes, diet, and behavior. Physiol Rev. 2002:82:637-72.

13. Ahmet I, Wan R, Mattson MP, et al. Cardioprotection by intermittent fasting in rats. Circulation. 2005;112:3115-21.

14. Katare RG, Kakinuma $Y$, Arikawa $M$, et al. Chronic intermittent fasting improves the survival following large myocardial ischemia by activation of BDNFNEGF/PI3K signaling pathway. J Mol Cell Cardiol. 2009:46:405-12.

15. Guizoni DM, Oliveira-Junior SA, Noor SL, et al. Effects of late exercise on cardiac remodeling and myocardial calcium handling proteins in rats with moderate and large size myocardial infarction. Int J Cardiol. 2016;221:406-12.
16. Martinez PF, Bonomo C, Guizoni DM, et al. Influence of N-acetylcysteine on oxidative stress in slow-twitch soleus muscle of heart failure rats. Cell Physiol Biochem. 2015;35:148-59.

17. Damatto RL, Martinez PF, Lima AR, et al. Heart failure-induced skeletal myopathy in spontaneously hypertensive rats. Int J Cardiol. 2013;167:698-703.

18. Oliveira Junior SA, Dal Pai-Silva M, Martinez PF, et al. Diet-induced obesity causes metabolic, endocrine and cardiac alterations in spontaneously hypertensive rats. Med Sci Monit. 2010;16:BR367-73.

19. Cezar MD, Damatto RL, Pagan LU, et al. Early spironolactone treatment attenuates heart failure development by improving myocardial function and reducing fibrosis in spontaneously hypertensive rats. Cell Physiol Biochem. 2015;36:1453-66.

20. Gimenes R, Gimenes C, Rosa CM, et al. Influence of apocynin on cardiac remodeling in rats with streptozotocin-induced diabetes mellitus. Cardiovasc Diabetol. 2018;17:15.

21. Polegato BF, Minicucci MF, Azevedo PS, et al. Acute doxorubicin-induced cardiotoxicity is associated with matrix metalloproteinase-2 activation in rats. Cell Physiol Biochem. 2015;35:1924-33.

22. Okoshi K, Fioretto JR, Okoshi MP, et al. Food restriction induces in vivo ventricular dysfunction in spontaneously hypertensive rats without impairment of in vitro myocardial contractility. Braz J Med Biol Res. 2004:37:607-13.

23. Fioretto JR, Queiroz SS, Padovani $C R$, et al. Ventricular remodeling and diastolic myocardial dysfunction in rats submitted to protein-calorie malnutrition. Am J Phys. 2002;282:H1327-33.

24. Pagan LU, Damatto RL, Cezar MD, et al. Long-term low intensity physical exercise attenuates heart failure development in aging spontaneously hypertensive rats. Cell Physiol Biochem. 2015;36:61-74.

25. Rosa CM, Gimenes R, Campos DH, et al. Apocynin influence on oxidative stress and cardiac remodeling of spontaneously hypertensive rats with diabetes mellitus. Cardiovasc Diabetol. 2016;15:126.

26. Reyes DRA, Gomes MJ, Rosa CM, et al. N-acetylcysteine influence on oxidative stress and cardiac remodeling in rats during transition from compensated left ventricular hypertrophy to heart failure. Cell Physiol Biochem. 2017:44:2310-21.

27. Cezar MD, Damatto RL, Martinez PF, et al. Aldosterone blockade reduces mortality without changing cardiac remodeling in spontaneously hypertensive rats. Cell Physiol Biochem. 2013;32:1275-87.

28. Okoshi MP, Matsubara LS, Franco M, et al. Myocyte necrosis is the basis for fibrosis in renovascular hypertensive rats. Braz J Med Biol Res. 1997;30:1135-44.

29. Cicogna AC, Padovani CR, Okoshi $K$, et al. The influence of temporal food restriction on the performance of isolated cardiac muscle. Nutr Res. 2001;21:639-48.

30. Martinez PF, Bonomo C, Guizoni DM, et al. Modulation of MAPK and NFkappaB signaling pathways by antioxidant therapy in skeletal muscle of heart failure rats. Cell Physiol Biochem. 2016;39:371-84.

31. Lima AR, Martinez PF, Damatto RL, et al. Heart failure-induced diaphragm myopathy. Cell Physiol Biochem. 2014;34:333-45.

32. Gomes MJ, Martinez PF, Campos DHS, et al. Beneficial effects of physical exercise on functional capacity and skeletal muscle oxidative stress in rats with aortic stenosis-induced heart failure. Oxidative Med Cell Longev. 2016; 2016:8695716

33. Reyes DRA, Gomes MJ, Rosa CM, Pagan LU, Zanati SG, Damatto RL, et al Exercise during transition from compensated left ventricular hypertrophy to heart failure in aortic stenosis rats. J Cell Mol Med. 2019:23:1235-45.

34. Fontana $L$, Partridge $L$, Longo VD. Extending healthy life span - from yeast to humans. Science. 2010:328:321-6.

35. Niemann $B$, Chen $Y$, Issa $H$, et al. Caloric restriction delays cardiac ageing in rats: role of mitochondria. Cardiovasc Res. 2010;88:267-76.

36. Shinmura K, Tamaki K, Bolli R. Impact of 6-mo caloric restriction on myocardial ischemic tolerance: possible involvement of nitric oxide-dependent increase in nuclear sirt1. Am J Physiol Heart Circ Physiol. 2008;295:H2348-55.

37. Shinmura K, Tamaki K, Bolli R. Short-term caloric restriction improves ischemic tolerance independent of opening of ATP-sensitive $\mathrm{K}^{+}$channels in both young and aged hearts. J Mol Cell Cardiol. 2005;39:285-96.

38. Ahmet I, Tae HJ, de Cabo R, et al. Effects of calorie restriction on cardioprotection and cardiovascular health. J Mol Cell Cardiol. 2011;51:263-71.

39. Seymour EM, Parikh RV, Singer AA, Bolling SF. Moderate calorie restriction improves cardiac remodeling and diastolic dysfunction in the dahl-SS rat. J Mol Cell Cardiol. 2006:41:661-8.

40. Okoshi MP, Okoshi K, Matsubara LS, et al. Myocardial remodeling and dysfunction are induced by chronic food restriction in spontaneously hypertensive rats. Nutr Res. 2006;26:567-72. 
41. Castello L, Froio T, Maina M, et al. Alternate-day fasting protects the rat heart against age-induced inflammation and fibrosis by inhibiting oxidative damage and NF-kB activation. Free Radic Biol Med. 2010;48:47-54.

42. Ahmet I, Wan R, Mattson MP, et al. Chronic alternate-day fasting results in reduced diastolic compliance and diminished systolic reserve in rats. J Card Fail. 2010;16:843-53

43. Martinez PF, Okoshi K, Zornoff LA, et al. Echocardiographic detection of congestive heart failure in postinfarction rats. J Appl Physiol. 2011;111:543-51.

44. Minicucci MF, Azevedo PS, Martinez PF, et al. Critical infarct size to induce ventricular remodeling, cardiac dysfunction and heart failure in rats. Int J Cardiol. 2011;151:242-3.

45. Mann DL. Pathophysiology of heart failure. In: Bonow RO, Mann DL, Zipes DP, Libby P, Braunwald E, editors. Braunwald's heart disease. Philadelphia: Elsevier Saunders; 2012. p. 487-504.

\section{Publisher's Note}

Springer Nature remains neutral with regard to jurisdictional claims in published maps and institutional affiliations.

Ready to submit your research? Choose BMC and benefit from:

- fast, convenient online submission

- thorough peer review by experienced researchers in your field

- rapid publication on acceptance

- support for research data, including large and complex data types

- gold Open Access which fosters wider collaboration and increased citations

- maximum visibility for your research: over $100 \mathrm{M}$ website views per year

At BMC, research is always in progress.

Learn more biomedcentral.com/submissions 